\title{
The effects of school life, emotional intelligence, and social intelligence on resilience of nursing university students.
}

\author{
Su-Jin Won ${ }^{1}$, Chung-Uk Heo ${ }^{2}$, Young-Soon $\mathrm{Choi}^{3}$ * \\ ${ }^{1}$ Department of Nursing, Kyungdong University, 815, Mumak-eup, Wonju, Republic of Korea \\ ${ }^{2}$ Department of Tourism, Kangwon National University, Samcheok-si, Republic of Korea \\ ${ }^{3}$ Department of Nursing, College of Health Science, Kangwon National University, Samcheok-si, \\ Republic of Korea
}

\begin{abstract}
This study is a descriptive correlation study to investigate the demographic characteristics, school life, emotional intelligence, social intelligence, and resilience of nursing university students and to identify the factors affecting the correlation and resilience of each variable. The results showed that emotional intelligence was 3.46, social intelligence was 3.80 , and resilience was 3.75 . There was a statistically significant difference in resilience according to religion, academic motivation, grades, and major satisfaction. The emotional intelligence of the subjects had a statistically significant positive correlation with social intelligence, resilience, resilience-control, resilience-positively, resilience-sociality. Social intelligence has a statistically significant positive correlation with resilience, resilience-control, resiliencepositive, resilience-sociality, and resilience. Resilience had a statistically significant positive correlation with resilience-control, resilience-positive-positive, resilience-sociality. Resilience-control had a statistically significant positive correlation with resilience-positive and resilient-sociality. Resiliencepositive had a statistically significant positive correlation with resilience-sociality. The results of this study showed that resilience, emotional intelligence, and social intelligence are related. Therefore, in order to improve the resilience of university students, a life management strategy considering emotional intelligence and social intelligence will be needed.
\end{abstract}

Keywords: School life, Emotional intelligence, Social intelligence, Resilience, Nursing university students. Accepted on November 30, 2018

\section{Introduction}

The term "emotional intelligence" was first used by Salovey and Mayer. They defined it as abilities to check the feelings and emotions of one's own and others, to notice the differences in those regards and to make use of emotional information for thinking and acting on the assumptions that emotional information is intervened in solving various cognitive and social problems, that the way of processing this information is different from that of processing cognitive information, and that there are individual variances in information [1].

Emotional intelligence plays positive roles in relieving negative psychological traits like stress or depression, in building good human relationships and in facilitating adjustment to family and school lives [1,2]. In fact, however, social climate that prioritizes school grades, employment and academic credential provides negative experiences to college students such as negative psychology, negative emotions, selfish individualism, a loss of ego-identity, realistic utilitarianism, a loss of humanity, a lack of sound consciousness, unestablished values, cultural immaturity, a loss of individuality and a loss of diversity [3].

As for social intelligence, Thorndike classified human intelligence into abstract intelligence, mechanical intelligence, and social intelligence, regarding social intelligence as an independent intelligence. He defined it as abilities to understand the behaviors of others, to deal with the given social clue and to be wise in human relationships [4].

Social intelligence as sociocognitive flexibility and the complexity of social knowledge. It's said that those whose social intelligence is good are able to store and organize complicated social information in a sophisticated way, to have the right understanding of social incidents and others, and thereby to properly respond to the social circumstances [5].

Social intelligence exercises positive influences on understanding in social settings others who are different from oneself, on behaving in a manner to be proper for others and different situations, on communicating with them effectively, 
on actively resolving problems with interpersonal relationships, and on having an open and flexible attitude [6,7].

Resiliency means "the strength to take advantage of various adversities and hardships that one encounters as the opportunity to leap forward" [8]. That is not what one is born with but a dynamic concept that involves the positive response to changes and challenging environments and individual development [9], and that features being generated, maintained or extinct [10]. Resiliency is comprehensive of self-regulation, which is to be aware of and regulate one's own emotions, of interpersonal skills, which are to be quick to find out the psychological and emotional state of others, to have a lot of sympathy with them and to build and keep good relationships with them, and of positivity, which is to have positive expectations and feel satisfaction [7].

Under the circumstances, the importance of emotional intelligence and social intelligence that are linked to the resiliency of university students should urgently be realized, and an effort to develop it is desperately required. The purpose of this study was to examine the influence of emotional intelligence and social intelligence, which are positive characteristics, to resiliency based on their relationships in an attempt to provide some educational materials on how to boost emotional intelligence, social intelligence, and resiliency.

\section{Research Method}

\section{Research design}

This study is a descriptive correlation study to investigate the demographic characteristics, emotional intelligence, social intelligence, and resilience of university students and to identify the factors affecting the correlation and resilience of each variable.

\section{Research subjects}

The subjects of this study were college students attending $G$ university in Gangwon province. The sample size was calculated using the $\mathrm{G} *$ power 3.1 programs. The effect size was 0.20 , significance level 0.05 , the power of 0.95 , and regression analysis. Considering the dropout rate $(10 \%)$, the number of subjects was 242, and the final 250 questionnaires were analysed except for the two questionnaires.

\section{Research tools}

The general characteristics consisted of 9 items of gender, age, grade, religion, residence type, club activities, part-time, smoking, drinking, the friend of the opposite sex. The major characteristics were composed of 3 items including motivation, grade, and major satisfaction.

The resilience measurement tool was YKRQ-27 scale developed by Kim and others and was used as modified and supplemented by Huh [11]. This scale consisted of 27 items (9 items) (impulse control, audit causal analysis, life satisfaction, relationship, emotion control, optimism, communication ability, empathy ability) of 3 types, And each item is composed of 5 points 'Likely', 4 points 'Yes', 3 points 'Normal', 2 points 'No', and 1 point 'Not at all' as 5 points Likert scale. The reliability of the Huh Yun-young's study was Cronbach's $\alpha=0.928$, and Cronbach's $\alpha=0.931$ in this study.

Emotional intelligence measurement tools were modified and supplemented by Kim [12], a standardized emotional intelligence measurement tool developed by Moon [10], based on the recent emotional intelligence model of Salovey et al. [1]. These items consist of emotional awareness and expression, empathy, thinking facilitation, emotional utilization, and emotional control. Each item is 5 points of Likert 5 point scale from 'not at all' to 'very agree' It consists of 23 questions. The reliability of the Kim's study was Cronbach's $\alpha=0.792$ and Cronbach's $\alpha=0.803$ in this study.

The social intelligence measurement tool used the research tool modified by Kim to make the social intelligence measurement tool of Park et al. applicable to adolescents [8]. The tool consisted of social efficacy, social support, social insight, social expression, and social behavior. Each item is a 5-point Likert scale with 5 items from 'Not at all' to 'Very highly' and consists of 24 items. The reliability of the Kim's study was Cronbach's $\alpha=0.739$ and Cronbach's $\alpha=0.894$ in this study.

\section{Procedure of data collection}

The data collection period of this study was from April 1, 2018 , to June 30 , before collecting the data, the purpose of the study, the data collection and the method of discarding the data at the end of the study were explained, and then the questionnaire was conducted after receiving the written consent from the person who wanted to participate. Explain that the questionnaire can be discontinued when withdrawing from the study during the questionnaire preparation, and guided that there is no disadvantage. The average time spent in the questionnaire was $10 \sim 15 \mathrm{~min}$.

\section{Statistical analysis}

The collected data are analysed using the SPSS 21.0 program as follows. 1) The resilience, emotional intelligence, and emotional intelligence according to the demographic and sociological characteristics of the subjects were analysed by descriptive statistics, t-test, and ANOVA, and Scheff'e test was used for post-test. 2) Pearson's correlation was used to analyse the relationship between recovery elasticity, emotional intelligence, and emotional intelligence. 3) The effect of the subject's emotional intelligence and emotional intelligence on resilience was analysed by the hierarchical method with multiple regression.

\section{Results}

\section{Analysis of subject's emotional intelligence, social intelligence, and resilience}

The emotional intelligence of the subjects was $(3.46 \pm 0.36)$ on the scale of 5 , and the social intelligence was $(3.80 \pm 0.49)$ on 
the scale of 5 and the resilience was $(3.75 \pm 0.56)$ on the scale of 5. Emotional input was the highest with $(3.76 \pm 0.55)$ in the sub-items of emotional intelligence, the emotional adjustment was lowest at $(2.88 \pm 0.78)$. In sub-items of social intelligence, social insight was the highest at $(4.10 \pm 0.54)$, social support was lowest at $(3.50 \pm 0.71)$. In the subscale of resilience, the social relationship was the highest at $(4.24 \pm 0.73)$ and the impulsive inhibition was lowest at $(3.31 \pm 0.81)$ (Table 1$)$.

\section{Resilience according to general characteristics}

The resilience according to the general characteristics of the subjects was statistically significant according to religion, academic motivation, grade, and major satisfaction. The average score of religion was 4.01 in Catholicism, 3.81 in Christianity, 3.76 in Buddhism, and 3.68 in Buddhism. As a result of the post-test Catholics were more resilience than Christian, Buddhist, and Buddhist groups $(\mathrm{F}=2.71, \mathrm{p}=0.045)$. The average score of department choice motive was 3.90 points for self-aptitude, 3.67 points for job prospect, 3.67 points for circumference invitation, and 3.65 points for others. As a result of the post-test, students who selected the department as their aptitude was found to have high resilience $(\mathrm{F}=3.53, \mathrm{p}=0.015)$. The mean scores of the grades were 3.87 points score is over 4.0, ' $3.51-4.0$ ' was 3.82 points, ' $3.01-3.5$ ' was 3.72 points, and below 3.0 was 3.53 points. The post-test results showed that the higher the grades, the higher the resilience $(F=3.07, p=0.025)$. Major satisfaction means scores were 'highly satisfaction' was 4.24 points, 'little satisfaction' was 3.79 points, 'ordinary' was 3.51 points, 'dissatisfaction' was 3.64 point. As a result of post-test, when satisfied that showed high resilience than the case of unsatisfactory or normal $(\mathrm{F}=24.91, \mathrm{p}<0.001)$ (Table 2).

\section{Correlation between emotional intelligence, social intelligence and resilience of subjects}

The emotional intelligence of the subjects was significantly positive correlated with social intelligence $(\mathrm{r}=0.582, \mathrm{p}<0.001)$, resilience $(\mathrm{r}=0.686, \mathrm{p}<0.001)$, resilience- control $(\mathrm{r}=0.633$, $\mathrm{p}<0.001), \quad$ resilience-positive $\quad(\mathrm{r}=0.568, \quad \mathrm{p}<0.001) \quad$ and resilience-sociality $(\mathrm{r}=0.530, \mathrm{p}<0.001)$.

Social intelligence of the subjects was significantly positive correlated with resilience $(\mathrm{r}=0.710, \mathrm{p}<0.001)$, resiliencecontrol $(\mathrm{r}=0.541, \mathrm{p}<0.001)$, resilience-positive $(\mathrm{r}=0.646$, $\mathrm{p}<0.001)$, and resilience-sociality $(\mathrm{r}=0.589, \mathrm{p}<0.001)$.

Resilience of the subjects was significantly positive correlated with resilience-control $(r=0.827, p<0.001)$, resilience-positive $(\mathrm{r}=0.873, \mathrm{p}<0.001)$ and resilience-sociality $(\mathrm{r}=0.812, \mathrm{p}<0.001)$. Resilience-control the subjects was significantly positive correlated with the resilience-positive $(\mathrm{r}=0.600, \mathrm{p}<0.001)$, resilience-sociality $(\mathrm{r}=0.513, \mathrm{p}<0.001)$, Resilience-positive the subjects was significantly positive correlated with resiliencesociality $(\mathrm{r}=0.544, \mathrm{p}<0.001)$ (Table 3$)$.

Table 1. Analysis of subject's emotional intelligence, social intelligence, and resilience $(N=250)$.

\begin{tabular}{|c|c|c|c|c|}
\hline Variables & Mean \pm SD & Min & Max & $\begin{array}{l}\text { Cronbach's } \\
\alpha\end{array}$ \\
\hline Emotional intelligence-total & $3.46 \pm 0.36$ & 2.54 & 4.49 & 0.803 \\
\hline $\begin{array}{l}\text { Emotional recognition and } \\
\text { expression }\end{array}$ & $3.74 \pm 0.50$ & 2.57 & 5 & \\
\hline Emotional empathy & $3.76 \pm 0.55$ & 2.29 & 5 & \\
\hline promotion of thinking; & $3.65 \pm 0.53$ & 2.13 & 5 & \\
\hline emotional utilization & $3.3 \pm 0.64$ & 1.67 & 5 & \\
\hline Emotional control & $2.88 \pm 0.78$ & 1 & 4.8 & \\
\hline Social intelligence-total & $3.8 \pm 0.49$ & 2.42 & 5 & 0.894 \\
\hline Social efficacy & $3.69 \pm 0.68$ & 2 & 5 & \\
\hline Social support & $3.5 \pm 0.71$ & 1.2 & 5 & \\
\hline Social insight & $4.1 \pm 0.54$ & 2.33 & 5 & \\
\hline Social expression & $3.82 \pm 0.69$ & 1.8 & 5 & \\
\hline Social behavior & $3.83 \pm 0.68$ & 2 & 5 & \\
\hline Resilience-total & $3.75 \pm 0.56$ & 2.3 & 5 & 0.931 \\
\hline 1) Control & $3.53 \pm 0.61$ & 1.67 & 5 & \\
\hline Cause analysis ability & $3.75 \pm 0.68$ & 1.67 & 5 & \\
\hline Emotional control & $3.53 \pm 0.69$ & 1.67 & 5 & \\
\hline Impulse control & $3.31 \pm 0.82$ & 1.33 & 5 & \\
\hline 2) Positivity & $3.82 \pm 0.75$ & 1.22 & 5 & \\
\hline Thanks, & $4.04 \pm 0.84$ & 1 & 5 & \\
\hline Satisfaction with living & $3.51 \pm 1.00$ & 1 & 5 & \\
\hline Optimism & $3.9 \pm 0.80$ & 1 & 5 & \\
\hline 3) Sociality & $3.9 \pm 0.64$ & 2.22 & 5 & \\
\hline Relativity & $4.24 \pm 0.73$ & 1.33 & 5 & \\
\hline Communication ability & $3.58 \pm 0.89$ & 1.67 & 5 & \\
\hline Empathy & $3.88 \pm 0.71$ & 2 & 5 & \\
\hline
\end{tabular}

Table 2. Analysis of subject's emotional intelligence, social intelligence, and resilience.

\begin{tabular}{|c|c|c|c|c|c|c|c|c|c|}
\hline Variables & Categories & Mean \pm SD & $t$ or $F$ & $\mathbf{p}$ & Variables & Categories & Mean \pm SD & $t$ or $F$ & $\mathbf{p}$ \\
\hline \multirow[t]{2}{*}{ Gender } & Male & $3.81 \pm 0.58$ & 0.75 & 0.456 & $\begin{array}{l}\text { Friend of the } \\
\text { opposite sex }\end{array}$ & No & $3.7 \pm 0.52$ & -1.49 & 0.137 \\
\hline & Female & $3.74 \pm 0.56$ & & & & Yes & $3.81 \pm 0.61$ & & \\
\hline
\end{tabular}




\begin{tabular}{|c|c|c|c|c|c|c|c|c|c|}
\hline \multirow[t]{4}{*}{ Religion } & Christian & $3.81 \pm 0.55^{a b}$ & 2.71 & \multirow[t]{4}{*}{0.045} & \multirow{4}{*}{$\begin{array}{l}\text { Department } \\
\text { selection motive }\end{array}$} & Identity & $3.9 \pm 0.57^{a}$ & \multirow{4}{*}{$\begin{array}{l}3.53 \\
(a>b)\end{array}$} & \multirow[t]{4}{*}{0.016} \\
\hline & Catholic & $4.01 \pm 0.54^{b}$ & \multirow[t]{3}{*}{$(a<b)$} & & & $\begin{array}{l}\text { Parent teacher } \\
\text { authority }\end{array}$ & $3.65 \pm 0.45^{b}$ & & \\
\hline & Buddhism & $3.76 \pm 0.67^{a b}$ & & & & Job prospects & $3.67 \pm 0.58^{b}$ & & \\
\hline & None & $3.68 \pm 0.54^{a}$ & & & & Other & $3.65 \pm 0.55^{b}$ & & \\
\hline \multirow[t]{2}{*}{ Lives with } & Yes & $3.72 \pm 0.53$ & \multirow[t]{2}{*}{-0.63} & \multirow[t]{2}{*}{0.531} & \multirow[t]{4}{*}{ Grades } & $\leq 3.00$ & $3.53 \pm 0.60^{\mathrm{a}}$ & 3.07 & 0.028 \\
\hline & No & $3.76 \pm 0.57$ & & & & $3.01 \sim 3.50$ & $3.72 \pm 0.59^{a b}$ & $(a<b)$ & \\
\hline \multirow[t]{2}{*}{ Club activity } & No & $3.66 \pm 0.53$ & \multirow[t]{2}{*}{-1.7} & \multirow[t]{2}{*}{0.091} & & $3.51 \sim 4.00$ & $3.82 \pm 0.51^{b}$ & & \\
\hline & Yes & $3.79 \pm 0.57$ & & & & $\geq 4.01$ & $3.87 \pm 0.52^{b}$ & & \\
\hline \multirow[t]{2}{*}{ Part-time job } & No & $3.76 \pm 0.55$ & \multirow[t]{2}{*}{0.43} & \multirow[t]{2}{*}{0.67} & \multirow[t]{4}{*}{ Major satisfaction } & little dissatisfaction & $3.54 \pm 0.53^{a}$ & 24.91 & $<0.001$ \\
\hline & Yes & $3.73 \pm 0.59$ & & & & ordinary & $3.51 \pm 0.49^{a}$ & $(a<b<c)$ & \\
\hline \multirow[t]{2}{*}{ Smoking } & No & $3.76 \pm 0.55$ & \multirow[t]{2}{*}{1.3} & \multirow[t]{2}{*}{0.195} & & little satisfaction & $3.79 \pm 0.49^{b}$ & & \\
\hline & Yes & $3.5 \pm 0.80$ & & & & highly satisfaction & $4.24 \pm 0.48^{c}$ & & \\
\hline \multirow[t]{2}{*}{ Drinking } & No & $3.68 \pm 0.54$ & \multirow[t]{2}{*}{-1.62} & \multirow[t]{2}{*}{0.107} & & & & & \\
\hline & Yes & $3.8 \pm 0.57$ & & & & & & & \\
\hline
\end{tabular}

Table 3. Correlation between subject's characteristics.

\begin{tabular}{|c|c|c|c|c|c|c|}
\hline & $\begin{array}{l}\text { Emotional } \\
\text { intelligence }\end{array}$ & Social intelligence & Resilience & Resilience control & $\begin{array}{l}\text { Resilience } \\
\text { positivity }\end{array}$ & $\begin{array}{l}\text { Resilience } \\
\text { sociality }\end{array}$ \\
\hline \multirow[t]{2}{*}{ Emotional intelligence } & 1 & $0.582^{* *}$ & $0.686^{* *}$ & $0.633^{* *}$ & $0.568^{* *}$ & $0.530^{* *}$ \\
\hline & & $<0.001$ & $<0.001$ & $<0.001$ & $<0.001$ & $<0.001$ \\
\hline \multirow[t]{2}{*}{ Social intelligence } & & 1 & $0.710^{* *}$ & $0.541^{* *}$ & $0.646^{* *}$ & $0.589^{* *}$ \\
\hline & & & $<0.001$ & $<0.001$ & $<0.001$ & $<0.001$ \\
\hline \multirow[t]{2}{*}{ Resilience total } & & & 1 & $0.827^{* *}$ & $0.873^{* *}$ & $0.812^{\star *}$ \\
\hline & & & & $<0.001$ & $<0.001$ & $<0.001$ \\
\hline \multirow[t]{2}{*}{ Resilience control } & & & & 1 & $0.600^{* *}$ & $0.513^{* *}$ \\
\hline & & & & & $<0.001$ & $<0.001$ \\
\hline \multirow[t]{2}{*}{ Resilience positivity } & & & & & 1 & $0.544^{* *}$ \\
\hline & & & & & & $<0.001$ \\
\hline Resilience sociality & & & & & & 1 \\
\hline
\end{tabular}

\section{Discussion}

The emotional intelligence of the subjects was 3.46 points on the 5 points scale, social intelligence was 3.80 points on the 5 points scale, and the resilience was 3.75 points on the 5 points scale.

In the sub-items of emotional intelligence, emotional input was highest at 3.76 points out of 5 points emotional regulation was lowest at 2.88 points out of 5 points. In the study of Jung for high school students, emotion expression was high in male and empathy was high in the female. This is consistent with Jung's study because it is said that the subject of the research is the woman with the highest score of empathy [13].

The resilience according to the general characteristics of the subjects was statistically significant according to religion, academic motivation, grade, and major satisfaction. In the Catholic religion, it was identified as a high resilience compared to the group with no religion. Religion has emotional stability, and it seems that this emotional stability helps to overcome difficulties. The motivation for choosing the department is that the student who selected the department by his/her aptitude is found to have high resilience, and the decision of the department by himself/herself is highly satisfied 
with himself/herself. Also found that the higher the grade the higher resilience. Resilience was found to be higher than dissatisfaction in satisfying major.

In Bang's study, there was a statistically significant difference in gender but there was no significant difference in this study [14]. However, the resilience score according to gender was consistent with a study in which male students were higher than female students [15], which is inferred to be due to social influences that make men more strengthened in the process of socialization.

The emotional intelligence of the subjects had a statistically significant positive correlation with social intelligence, resilience, resilience-control, resilience-positive, resiliencesocial. In the study of Hwang's, the positive correlation between emotional intelligence and resilience was found to be consistent with the results of this study [15]. In another study, it was concluded that the results of this study showed that all the sub-variables of the child's ego-resilience were highly positive correlated with all sub-variables of emotional intelligence [16].

Social intelligence showed statistically significant positive correlation with resilience, resilience-control, resiliencepositive, resilience-sociality, and social intelligence showed higher resilience as socialization tendency. Resilience showed statistically significant positive correlation with resiliencecontrol, resilience-positive, resilience-sociality. Resiliencecontrol showed a statistically significant positive correlation with resilience-positive, resilience-sociality, resilience-positive showed a statistically significant positive correlation with resilience-sociality, and the more positive the student, the higher the sociality.

\section{Conclusion}

There was the statistically significant difference in resilience according to religion, academic motivation, grades, and major satisfaction. The emotional intelligence of the subjects had a statistically significant positive correlation with social intelligence, resilience, resilience-control, resilience-positively, resilience-sociality. Social intelligence has a statistically significant positive correlation with resilience, resiliencecontrol, resilience-positive, resilience-sociality, and resilience. Resilience had the statistically significant positive correlation with resilience-control, resilience-positive-positive, resiliencesociality. Resilience-control had a statistically significant positive correlation with resilience-positive and resilientsociality. Resilience-positive had a statistically significant positive correlation with resilience-sociality.

The results of this study showed that resilience, emotional intelligence, and social intelligence are related. Therefore, in order to improve the resilience of university students, a life management strategy considering emotional intelligence and social intelligence will be needed.

\section{Conflict of Interest}

The authors report no conflicts of interest related to this study. The author does not have any financial interest in the companies whose materials are included in the article.

\section{References}

1. Salovey P, Mayer JD, Caruso D. The positive psychology of emotional intelligence. The Handbook of Positive Psychology NY: Oxford University Press 2001.

2. Mun YL. A study on emotional intelligence development program for personality education. Seoul Nat Univ Coll Edu J 1999; 59: 31-98.

3. Kim HG. A comparative study on the quality of life among elementary, middle and high school students in Incheon. Incheon Scholarship Foundation 2006a; 91-135.

4. Thorndike EL. Intelligence and its uses. Harper's Magaz 1920; 140: 227-235.

5. Lee JE. Social intelligence: flexibility and complexity and distinct from creativity. Unpublished Doctoral Dissertation University of Notre Dame 1999.

6. Han SY, Kang KS. Childrens social intelligence, mothers daregiving attitude, parental conflict, and peer bullyingvictimization. J Life Sci Res 2004; 8: 73-86.

7. Moon TH. The study on the development of social intelligence scale. J Child Educ 2009; 9: 127-141.

8. Shin WY, Choi MN, Kim JH. The effects of the three resilience factors on problematic online game uses. J Cybercommun Acad Soc 2009; 26: 117-148.

9. $\mathrm{Gu} \mathrm{Q}$, Day C. Teachers resilience: A necessary condition for effectiveness. Teaching Teacher Educ 2007; 23: 1302-1316.

10. Ahn MY, Sim MG. Correlation between emotion intelligence and social ability. J Inje Univ 2006; 21: 271-280.

11. Heo YY. The relationship between resilience and interpersonal satisfaction of adolescents with loss of parents. Korea University Masters Thesis 2012; 1-57.

12. Kim HJ. The effects of emotional intelligence and social intelligence on quality of life of adolescents. Inha University Doctoral Thesis 2007; 1-156.

13. Jeong YJ. The relationship among emotional intelligence, self-efficacy and school-related adjustment. Hongik University Masters Thesis 2003; 1-64.

14. Bang HS, Kim YH. The moderating effect of resilience on the relationship between career barriers and employment stress. Tourism Res 2017; 42: 111-140.

15. Hwang HE, Kang HM, Tak JH. The mediating effect of resilience on the relationship between emotional intelligence and optimism in early childhood teachers. Early Childhood Educ Res 2014; 34: 323-346.

16. Yang HY, Yang SG. The mediating effects of children's ego-resilience on the relationship between parents' person-oriented guidance and children's emotionalintelligence. Korean Child J 2013; 34: 83-99. 


\section{"Correspondence to}

Young-Soon Choi

Department of Nursing
College of Health Science

Kangwon National University

Republic of Korea 